Research Article

\title{
Iron and Folic Acid Supplementation Compliance and Associated Factors among Pregnant Women Attending Antenatal Clinic in Shalla District, Southwest Ethiopia: A Cross-Sectional Study
}

\author{
Aman Kedir Obsa, ${ }^{1}$ Yadesse Tegene $\mathbb{D D}^{2},{ }^{2}$ and Achamyelesh Gebretsadik ${ }^{2}$ \\ ${ }^{1}$ Shalla District Health Office, Oromia, Ethiopia \\ ${ }^{2}$ Hawassa University College of Medicine and Health Science, Hawassa, Ethiopia
}

Correspondence should be addressed to Yadesse Tegene; yadessategene@yahoo.com

Received 24 December 2020; Revised 15 March 2021; Accepted 18 March 2021; Published 28 March 2021

Academic Editor: Roxana Valdés-Ramos

Copyright (c) 2021 Aman Kedir Obsa et al. This is an open access article distributed under the Creative Commons Attribution License, which permits unrestricted use, distribution, and reproduction in any medium, provided the original work is properly cited.

\begin{abstract}
Background. Iron-folate supplementation for a pregnant mother is a cost-effective intervention to reduce iron deficiency anemia during pregnancy. The aim of this study was to assess the iron-folic acid supplements and associated factors among pregnant women attending antenatal clinics in the public health center of Shalla district, Southwest Ethiopia. Methods. Institutional-based cross-sectional study design was conducted among 402 randomly selected pregnant mothers between February and April 2019. Data were collected using an interviewer-administered structured questionnaire from pregnant mothers attending antenatal care and using iron-folate supplements. Descriptive and multivariate logistic regression analyses were employed. Results. Pill count compliance rate was found to be (154) $38.3 \%$. Pregnant mothers who had anemia in their previous pregnancy [(AOR $=11.35,95 \%$ CI: 4.76-27.03)], counseling on iron-folate supplements [(AOR $=11.39,95 \% \mathrm{CI}$ : 5.09-27.03)], awareness of the benefit of the iron-folate supplements [(AOR $=2.22,95 \%$ CI: 1.18-3.92)], and being a member of the Health Development Army [(AOR $=2.11$, 95\% CI: $(1.2,3.9)]$ were significantly associated with compliance with iron-folate supplement. Conclusion. Compared to the World Health Organization cut-off point, the pill count compliance rate of iron-folate supplementation among pregnant women in the study area was very low. Previous history of anemia and lack of knowledge about its benefit were some of the factors associated with it. Therefore, the healthcare providers should give continuous awareness creation and counseling services focusing on the benefit of iron-folate supplementation for pregnant mothers and their neonates.
\end{abstract}

\section{Introduction}

Iron and folic acid supplementation for pregnant mothers are the main strategies to prevent anemia among pregnant mothers and newborns even though all the above intervention works depend on the context of the causes of anemia [1-3]. The World Health Organization has recommended a six-month regimen of a daily supplement containing $30-60 \mathrm{mg}$ of elemental iron with $400 \mu \mathrm{g}$ folic acid which is supplied to pregnant mothers during the first trimester or as soon as possible later on and it is provided when pregnant mothers come for antenatal care $[3,4]$. In areas where the prevalence of anemia in pregnant mothers is $>40 \%$, anemia is a severe public health problem. Iron and folic acid supplementation should continue for three months in the postpartum period. Accordingly, in Ethiopia, the national guideline for control and prevention of micronutrient deficiency also recommends daily iron supplementation for 180 days during pregnancy or it could be finished after delivery if the mother did not finish the full dose during pregnancy $[3,5]$.

Compliance with the medication regimen is generally defined as the extent to which a patient takes medication as prescribed by their healthcare providers [6]. Increasing compliance with the medication has a greater effect on health than improvement in a specific therapy. On the contrary, noncompliance which is not taking medication as prescribed by a healthcare provider is the main obstacle to 
effective medical treatment. According to the World Health Organization report, noncompliance with any medication treatment varies from $15 \%$ to $93 \%$, with an average estimated rate of $50 \%[6]$.

Ethiopian Demographic Health Survey (EDHS 2011) showed that, from all pregnant mothers supplemented with iron and folic acid tablet, only $0.4 \%$ consumed it for $>90$ days during their pregnancy time [7]. The EDHS 2016 finding also revealed that only $5 \%$ of pregnant mothers who gave birth five years before the survey took the supplements for the recommended period of time [8]. Therefore, the aim of this study was to assess the iron-folic acid supplements and associated factors among pregnant women attending antenatal clinics in the public health centers of Shalla district, Southwest Ethiopia.

\section{Materials and Methods}

2.1. Study Design, Period, and Setting. An institutional-based cross-sectional study was conducted in Shalla district, West Arsi Zone, which is found in the Oromia region of Ethiopia between February and April 2019. The district is one of the 20 districts in West Arsi Administrative Zone of Oromia located $280 \mathrm{~km}$ from the capital city, Addis Ababa, Ethiopia. According to projections based on the 2018 central statistical authority (CSA) population census of Ethiopia and district Health office data, the estimated total population for the year 2018 was 201,727 ( $8 \%$ urban and $92 \%$ rural), of whom 7,008 were pregnant women. The health service coverage of the district was $95 \%$. In the district, there are 8 health centers, 38 health posts, and 5 private clinics [9]. Seven of the health centers, which are found in the district, provide free of charge regular antenatal care follow-up and iron-folate supplementation for the period of six months during pregnancy and the postpartum period.

2.2. Study Population. Pregnant women attending ANC clinics in selected public health centers of Shalla district during the data collection period who had at least one ANC visit in health centers, supplemented with IFA tablets for at least one month before the date of the interview and brought back a bottle of pills, were included in the study. Pregnant women with a serious illness were excluded from the study.

2.3. Sample Size and Sampling Technique. The sample size for compliance with iron-folate supplement and associated factors was calculated by using the formula to estimate a single population proportions $n=(Z \cdot \alpha / 2)^{2} p(1-p) / d^{2}$, $n=$ sample size, $Z \cdot \alpha / 2=$ significance level at $\alpha=0.05$, $P=$ established prevalence from a previous study of the topic of interest (compliance) determinant of adherence to iron-folic acid supplementation among pregnant women attending antenatal clinic at Asella town $(p=59.8 \%)[10]$, and $d=$ the margin of error of 0.05 , with the assumptions of 95\% confidence interval; using the above single population proportion formula, the sample size was calculated as $n=(1.96)^{2} 0.392(0.608) /(0.05)^{2}=366$ and; considering a $10 \%$ nonrespondent rate, the total sample size was 402 . The total estimated number of pregnant women attending antenatal clinics in each health center was taken depending on the health center monthly plan, assuming that antenatal care attendants have a similar flow. The sample size was proportionally assigned to each health center. The total sample size of 402 pregnant women who took ferrous-folate supplements during the previous appointments was selected using systematic random sampling from the source population of 814 in the district during 32 days of data collection.

2.4. Dependent Variable. Dependent Variable was compliant with the IFA supplement.

\subsection{Independent Variables.}

Sociodemographic: age, marital status, household monthly income, family size, place of residence, maternal educational level, husband's education, and occupation

Obstetric factors: number of gravidae, parity, and number of ANC visits, abortion, previous history of anemia and ANC follow-up started time, and gestational age in months

Women awareness: awareness of anemia, awareness about the benefits of IFA, and awareness about the duration of the supplementation

Physical attributes and related factors: the side effects, forget fullness, unpleasant test, fear of big weight baby, and too many tabs harm infants

Healthcare system: problem faced in the facility, shortage of supplements in the facility, and health education

Health Development Army: organized groups of families who promote healthy activities and behavior among other families

2.6. Data Collection Methods and Procedures. The data collection instrument included six sections which are demographic, obstetrics history, knowledge on anemia and folic acid, compliance with iron and folic acid, and healthcare system factors. The questionnaire was developed by reviewing different literature and data were collected with a structured pretested questionnaire using an interview. The questionnaire was prepared in English and translated into Afaan Oromo and then back to English and compared for consistency. Data were collected by trained diploma midwives and interviewed pregnant mothers during antenatal care after getting consent.

2.7. Data Analysis. Data were entered using EpiData version 3.1 and analyzed using SPSS version 20. Compliance with the IFA supplement was assessed based on the pill count and self-report method. In the pill count method, mothers were given iron-folate for a period of one month and requested to bring back the bottle/container of the pill on the next 
appointment. Then, the bottle was checked for left pills in the bottle; if present, the number of pills in the bottle was counted, registered on a questionnaire, and considered as a number of pills expected to be taken/swallowed but not taken. In the self-report method, each pregnant woman was also assessed for the number of pills taken during the previous week before the interview. In both cases, compliance was defined as compliant if they took $70 \%$ or more of the prescribed supplements, which is equivalent to taking the supplements at least five days per week. The pill count method is more accurate than the self-reported method because it decreases the problem of recall bias $[6,11]$. But both methods of compliance measurement have an additive effect if used together. The one-month period was selected based on the duration of iron-folate given in the Shalla District health facility:

$$
\text { pill count compliance }(9)=\frac{\text { number of tablets taken in last month } \times 100}{\text { number of tablets prescribed in last month }} \text {. }
$$

Then, binary logistic regression was used to examine the relationship between the proposed predictors and compliance with iron-folate supplements. variable with $p$ value $\leq 0.25$ in the bivariate logistic regression analyses were considered as potential candidates in the final multivariable logistic regression analysis.

\subsection{Operational Definitions.}

Pregnant mothers' awareness about anemia: It was assessed using 15 questions. Respondents who scored above the mean were recorded as having good awareness of anemia.

Pregnant mothers' awareness about the benefits of IFA supplement: It was assessed using three questions. Those who correctly answered above the mean were recorded as having good awareness of the benefit of iron-folate supplements.

\section{Result}

A total of 402 pregnant mothers attending antenatal care and taking iron-folate supplements in the Shalla district were included in the study, yielding a response rate of $99 \%$. The mean age of the study participants was 25.21 ( \pm SD 5.96) years. Most of the study participants, 285 (71\%), were from a rural area, married 395 (98.3\%), and attending secondary school (27\%) (Table 1).

3.1. Past and Current Obstetrics Related Conditions. The gestational age of most of the study participants, pregnant mothers, ranges from 16 to 24 weeks; 226 (56\%) were on the third ANC visit, 153 (38\%) were multigravida, and 304 (76\%) had no previous history of abortion and stillbirth 363 (90\%). Majority of the study participants, 356 (89\%), never heard about the disease anemia but had no history of anemia in both the current and past delivery, 384 (95.5\%) and 249 (62\%), respectively (Table 2).

3.2. Comprehensive Awareness of Benefit of Iron-Folate Supplement and Anemia. The comprehensive awareness of the benefit of iron-folate was assessed using three questions; those who correctly answered above the mean were recorded as having good awareness. One hundred twelve (28\%) of the respondents had good awareness of the benefit of iron-folate supplements.

Compressive awareness of anemia was assessed using 15 questions: two questions on the symptom, four questions on the cause, four questions on the consequences, two questions on the susceptible group, and three questions on the prevention method; and each correct answer was given one point while wrong answers were given no points. Respondents scoring above the mean were recorded as having good awareness of anemia. Out of 356 respondents, 244 (69\%) had good awareness of anemia (Figure 1).

3.3. Supplemental Related Factors. The majority, 376 (95\%), of the interviewed pregnant mothers were taking their iron-folate supplements on a daily basis whereas 21 (5.2\%) took the supplements on a weekly basis and, and about 5 $(1.2 \%)$ took the supplements when they were sick (Table 3).

3.4. Health-Care-System-Related Factors. The majority of respondents, $183(45.4 \%)$, reported that it takes thirty minutes to one hour to reach the nearest health facility and $164(41 \%)$ respondents reported that it takes less than thirty minutes to reach the nearest health facility (Figure 2).

3.5. Compliance with Iron-Folate Supplement. Out of the total study participants, 154 (38.3\%) (95\% CI, 33.5\%-43.1\%) and $171(42.5 \%)(95 \% \mathrm{CI}, 37.7 \%-47.4 \%)$ respondents were compliant according to the pill count and self-report to iron-folate supplement, respectively (Figure 3 ).

3.6. Factors Associated with Compliance. In the bivariate logistic regression analysis, anemia in a previous pregnancy, counseling service given on the importance of IFA, awareness of the benefit of IFA, being a health development member in Kebele, and a previous history of delivery were significantly associated with compliance with iron-folate supplement at $p \leq 0.25$ and hence were used in the multivariate analysis.

Multiple logistic regression analyses revealing anemia in the previous pregnancy, counseling service given on the importance of IFA, awareness of the benefit of IFA, and 
TABLE 1: Sociodemographic characteristics of pregnant women attending antenatal care and taking iron-folate, Shalla district health facilities, West Arsi Zone, Southwest Ethiopia, 2019 $(N=402)$.

\begin{tabular}{lcc}
\hline Variables & Frequency & Percent \\
\hline Age & & \\
$15-20$ & 85 & 21 \\
$21-25$ & 137 & 34 \\
$26-30$ & 83 & 21 \\
$31-39$ & 97 & 24 \\
\hline Residence & & \\
Rural & 285 & 71 \\
Urban & 117 & 29 \\
\hline Marital status & & \\
Married & 395 & 98 \\
Widowed & 4 & 1 \\
Separated & 3 & 1 \\
\hline Educational status of the mother & & \\
Cannot write and read & 85 & 21 \\
Can write and read & 129 & 32 \\
Primary school 1-8 & 82 & 20 \\
Secondary school 9-10 & 74 & 18 \\
Above secondary & 32 & 8 \\
\hline Educational status of partner & & \\
Cannot write and read & 54 & 13 \\
Can write and read & 67 & 17 \\
Primary school 1-8 & 82 & 20 \\
Secondary school 9-10 & 107 & 27 \\
Above secondary & 92 & 23 \\
\hline
\end{tabular}

being a health development member remain to be significantly associated with compliance with iron-folate supplement. Pregnant mothers who had a history of anemia during their previous pregnancy were 6 times [ $(\mathrm{AOR}=6.13,95 \% \mathrm{CI}$ : $(2.9,12.9)]$ more likely to be compliant than pregnant mothers who had no history of anemia in their previous pregnancy. Pregnant mothers who had received counseling service given on iron-folate supplement were 8 times $[(\mathrm{AOR}=8.4,95 \% \mathrm{CI}:(4.5,15.5)]$ more likely to be compliant than those who did not receive counseling service. Study participants who had awareness of the benefit of iron-folate supplements nearly 2 times [( $\mathrm{AOR}=1.69,95 \% \mathrm{CI}:(1.0,2.9)$ ] were more likely to be compliant than those who did not have awareness of the benefit of iron-folate supplements. Those study participants who were members of the Health Development Army were also found to have two times more significant association $[(\mathrm{AOR}=2.11,95 \% \mathrm{CI}:(1.2,3.9)]$ than their counterparts (Table 4).

\section{Discussion}

In our study, $42.5 \%$ and $38.3 \%$ of the respondents were compliant with iron-folate supplements according to the self-report and pill count methods, respectively. The finding of the level of pill count compliance is consistent with a study conducted in Pakistan, which is 38.35 [12], but lower than the study conducted in Addis Ababa, Akaki Kality (61\%), and Egypt $(48.9 \%)[12,13]$, and higher than the study conducted in Uganda (11.6\%) [14]. The probable reason for
TABLE 2: Past and current obstetric history of pregnant women attending antenatal care and taking iron-folate, at Shalla district health facilities, West Arsi Zone, Southwest Ethiopia, 2019 $(N=402)$.

\begin{tabular}{|c|c|c|}
\hline Variables & Frequency & Percent \\
\hline $\begin{array}{l}\text { Gestational age at first antenatal visit } \\
\text { Less than } 16 \text { weeks } \\
16-24 \text { weeks } \\
25 \text { and above weeks }\end{array}$ & $\begin{array}{c}78 \\
226 \\
98 \\
\end{array}$ & $\begin{array}{l}19 \\
56 \\
24\end{array}$ \\
\hline $\begin{array}{l}\text { Number of antenatal visits } \\
\text { Second visit } \\
\text { Third visit } \\
\text { Fourth visit } \\
\text { Above fourth } \\
\end{array}$ & $\begin{array}{c}123 \\
153 \\
83 \\
43 \\
\end{array}$ & $\begin{array}{l}31 \\
38 \\
21 \\
11\end{array}$ \\
\hline $\begin{array}{l}\text { Previous history of delivery } \\
\text { Yes } \\
\text { No }\end{array}$ & $\begin{array}{c}304 \\
98 \\
\end{array}$ & $\begin{array}{l}76 \\
24 \\
\end{array}$ \\
\hline $\begin{array}{l}\text { Previous history of abortion } \\
\text { Yes } \\
\text { No }\end{array}$ & $\begin{array}{c}42 \\
360 \\
\end{array}$ & $\begin{array}{l}10 \\
90 \\
\end{array}$ \\
\hline $\begin{array}{l}\text { Previous history of stillbirth } \\
\text { Yes } \\
\text { No }\end{array}$ & $\begin{array}{c}39 \\
363 \\
\end{array}$ & $\begin{array}{l}10 \\
90 \\
\end{array}$ \\
\hline $\begin{array}{l}\text { Ever heard of anemia disease } \\
\text { Yes } \\
\text { No }\end{array}$ & $\begin{array}{c}356 \\
46 \\
\end{array}$ & $\begin{array}{l}89 \\
11 \\
\end{array}$ \\
\hline $\begin{array}{l}\text { Anemia in the current pregnancy } \\
\text { Yes } \\
\text { No }\end{array}$ & $\begin{array}{c}18 \\
384 \\
\end{array}$ & $\begin{array}{c}4.5 \\
95.5 \\
\end{array}$ \\
\hline $\begin{array}{l}\text { Anemia in a previous pregnancy }(N=304) \\
\text { Yes } \\
\text { No }\end{array}$ & $\begin{array}{c}55 \\
249 \\
\end{array}$ & $\begin{array}{l}38 \\
62 \\
\end{array}$ \\
\hline $\begin{array}{l}\text { Being Health Development Army } \\
\text { Yes } \\
\text { No }\end{array}$ & $\begin{array}{l}226 \\
176\end{array}$ & $\begin{array}{l}56 \\
44\end{array}$ \\
\hline
\end{tabular}

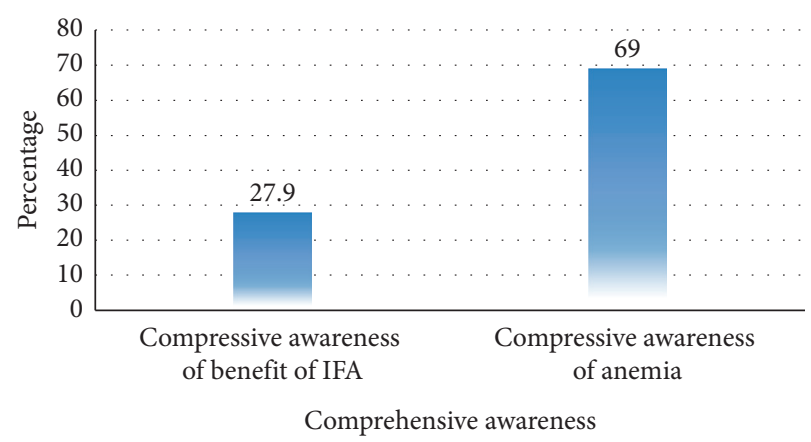

FIGURE 1: Compressive awareness of the benefit of IFA and anemia, among pregnant women attending antenatal care and taking ironfolate, Shalla district health facilities, West Arsi Zone, Southwest Ethiopia, 2019.

the difference could be attributed to the difference in sociodemographic variation. Compared to the World Health Organization cut-off point, compliance with iron-folate supplementation among pregnant women in the study area was low [6]. This could be due to supplemental factors associated with the drug, which make pregnant mothers skip their doses. 
TABLE 3: Reason for noncompliance with iron-folate supplements among pregnant women attending antenatal care and taking iron-folate, Shalla district health facilities, West Arsi Zone, Southwest Ethiopia, $2019(N=402)$.

\begin{tabular}{lcc}
\hline Variables & Frequency & Percent \\
\hline Reason for noncompliance with IFA & & 313 \\
Forgetfulness & 218 & 85.1 \\
Fear of pill side effect & 28 & 59.2 \\
Dislike test pill & 2 & 7.6 \\
Too many pills & & 0.5 \\
\hline Side effects preventing taking IFA & 137 & 64.0 \\
Epi gastric burning pain & 114 & 53.3 \\
Vomiting & 15 & 7.0 \\
Constipation & 3 & 1.4 \\
Diarrhea & & \\
\hline
\end{tabular}

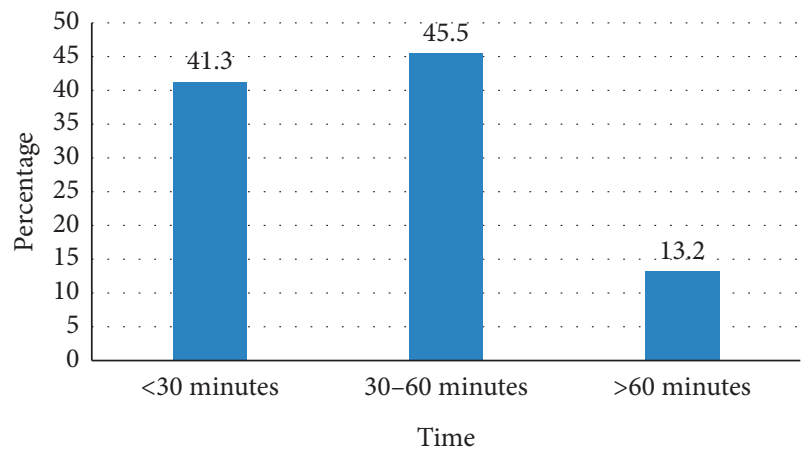

FIGURE 2: Time to reach the nearest health facilities from home among pregnant women attending antenatal care, Shalla district health facilities, West Arsi Zone, Southwest Ethiopia, 2011 $(N=402)$.

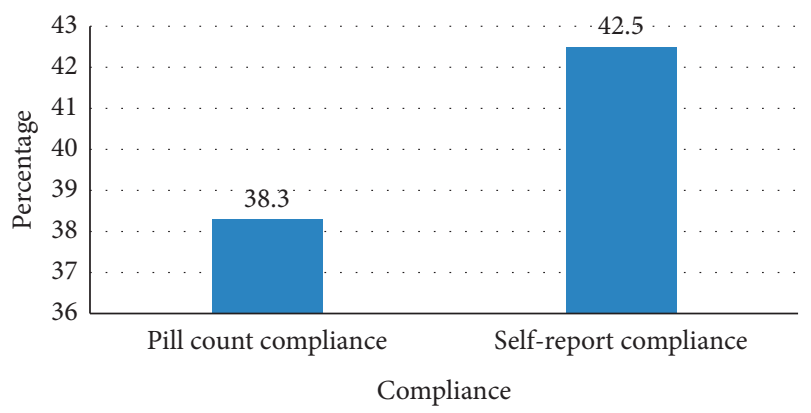

FIGURE 3: Compliance level with iron-folate supplement among pregnant women attending antenatal care and taking iron-folate, Shalla district health facilities, West Arsi Zone, Southwest Ethiopia, $2019(N=402)$.

Pregnant mothers who had anemia in their previous pregnancies were more compliant than their counterparts. The finding is consistent with a study conducted in the Tigray region and the Mecha District of the Amara region $[14,15]$. This could be due to the fact that experiencing symptoms of anemia in their previous pregnancy gave them awareness about the disease and to seek treatment in the present pregnancy.
Pregnant mothers, who got counseling service during their ANC visit on the benefit of iron-folate supplement, had higher odds of compliance than those who did not receive counseling service. This finding is in line with the study finding from Misha district, south Ethiopia, and the studies done in Kenya, India (Haryana state), Sweden, Cambodia, and Senegal $[1,16,17]$.

Having awareness of the benefit of iron-folate supplementation was also found to have an association with compliance with iron-folate supplementation. Study participants who had awareness of the benefit of iron-folate supplements had higher odds of compliance than their counterparts. A similar finding was obtained from the study conducted in Senegal and the Mecha district of the Amara region. $[13,14]$.

The other factor which has shown significant association with compliance with iron-folate supplementation was being a member of a Health Development Army. Those study participants who were members of the Health Development Army were two times more likely to be compliant with iron-folate supplementation than those who were not. Though there are no study reports which indicate an association between compliance with iron-folate supplementation and being a Health Development Army, there are studies which indicate the existence of a strong association between pregnant mothers with good knowledge about iron-folic acid supplement and compliance with iron-folate supplements during pregnancy $[15,18]$. The reason could be that knowledge helps women to have a good perception of iron-folic acid supplements.

Eighty-five percent of pregnant women who missed taking their supplementation were due to forgetfulness. This finding was higher than studies done on the Misha district of South Ethiopia (42.8\%) and India (48.8\%) [1, 19]. This difference may be due to the fact that the present study considers multiple responses, but the previous study allowed only one reason. In addition to this, provider differences in the geographic area and socioeconomic status of study participants may be the cause for the difference.

Even though the pill count compliance method was used to measure compliance, still there could be social desirability and recall bias, under/overestimated compliance rate. Generally, the gold standard measure of compliance is the 
TABLE 4: Multivariate logistic analysis of factors influencing compliance with iron-folate supplement among pregnant women attending ANC in Shalla district health facilities, West Arsi Zone, Ethiopia, $2019(N=402)$.

\begin{tabular}{|c|c|c|c|c|}
\hline \multirow{2}{*}{ Variables } & \multicolumn{2}{|c|}{ Compliance with iron-folate supplement } & \multirow{2}{*}{ COR $(95 \% \mathrm{CI})$} & \multirow{2}{*}{$\operatorname{AOR}(95 \% \mathrm{CI})$} \\
\hline & Compliant $N(\%)$ & Noncompliant $N(\%)$ & & \\
\hline \multicolumn{5}{|c|}{ Anemia in a previous pregnancy $(N=307)$} \\
\hline $\mathrm{No}^{\circledR}$ & $160(87.4)$ & $90(72.6)$ & $2.63(1.5-4.7)$ & $6.13(2.9,12.9)$ \\
\hline Yes & $23(12.6)$ & $34(27.4)$ & 1 & 1 \\
\hline \multicolumn{5}{|c|}{ Counseling service given on IFA } \\
\hline $\mathrm{No}^{\circledast}$ & $98(39.5)$ & $121(78.6)$ & 1 & 1 \\
\hline Yes & $150(60.5)$ & $33(21.4)$ & $5.61(3.6,8.9)$ & $8.4(4.5,15.5)$ \\
\hline \multicolumn{5}{|c|}{ Awareness of the benefit of IFA } \\
\hline $\mathrm{No}^{\circledR}$ & $188(75.8)$ & $102(66.2)$ & 1 & 1 \\
\hline Yes & $60(24.2)$ & $52(33.8)$ & $1.59(1.1,2.49)$ & $1.69(1.1-2.9)$ \\
\hline \multicolumn{5}{|c|}{ Member of Health Development Army } \\
\hline $\mathrm{No}^{\circledR}$ & $133(53.6 \%)$ & $133(53.6 \%)$ & 1 & \\
\hline Yes & $43(27.9 \%)$ & $43(27.9 \%)$ & $2.99(1.9,4.6)$ & $2.11(1.2,3.9)$ \\
\hline \multicolumn{5}{|c|}{ Previous history of delivery } \\
\hline $\mathrm{No}^{\circledR}$ & $67(27.0 \%)$ & $31(20.1 \%)$ & 1 & \\
\hline Yes & $181(73.0 \%)$ & $123(79.9 \%)$ & $1.5(0.9,2.4)$ & $1.07(0.1,15.4)$ \\
\hline
\end{tabular}

Statistically significant variables in multiple logistic regressions at $p$ value $\leq 0.05$. ${ }^{\circledR}$ Reference category. IFA, iron and folic acid; COR, crud odds ratio; AOR, adjusted odds ratio; CI, confidence interval.

electronic method, though it is difficult to implement in our setup because of its expensiveness.

\section{Conclusion}

In conclusion, pill count compliance rate, as well as selfreport compliance with iron-folate supplementation among pregnant women in the study area, was low compared to the World Health Organization cut-off point. Anemia in a previous pregnancy, counseling service given on IFA, awareness of the benefit of IFA, and being a member of the Health Development Army remain to be significantly associated with compliance with iron-folate supplement. In addition, forgetfulness and fear of side effects of the iron-folate supplements in the health facility were commonly mentioned reasons for missing the doses of the iron-folate supplements. Therefore, the healthcare providers should provide continuous awareness creation and counseling services focusing on the benefit of iron-folate for pregnant mothers and their neonates. In addition, household members should encourage and remind pregnant women to take their supplements on a daily basis.

\section{Abbreviations}

ANC: Antenatal care

CSA: Central Statistics Agency

DHS: Demographic Health Survey

EDHS: Ethiopian Demographic Health Survey

FA: $\quad$ Folic acid

HC: Health center

HDA: Health Development Army

Hgb: Hemoglobin

ID: Iron deficiency

IFA: Iron and folic acid
PW: Pregnant mother

SPSS: Statistical Package for Social Science

SRS: $\quad$ Simple random sampling

WHO: World Health Organization.

\section{Data Availability}

The datasets used and/or analyzed during the current study are available from the corresponding author on reasonable request.

\section{Ethical Approval}

The study protocol was reviewed and approved by the Hawassa University College of Medicine and Health Sciences Institutional Review Board (IRB). Written permission was also obtained from Oromia Regional State Health Bureau.

\section{Consent}

Informed verbal consent was obtained from every participant, pregnant mother, before the interview. The data were collected and analyzed anonymously.

\section{Conflicts of Interest}

The authors declare that they have no competing interests.

\section{Authors' Contributions}

AK, YT, and AG obtained the data, analyzed and wrote the original draft interpreted, and critically revised the manuscript. All the authors read and approved the final draft of the manuscript. 


\section{Acknowledgments}

The authors thank Hawassa University, College of Medicine and Health Sciences for facilitation for the study. The authors would like to thank also the data collectors and the study participants.

\section{References}

[1] A. Arega Sadore, L. Abebe Gebretsadik, and M. Aman Hussen, "Compliance with iron-folate supplement and associated factors among antenatal care attendant mothers in Misha District, South Ethiopia: community based cross-sectional study," Journal of Environmental and Public Health, vol. 2015, Article ID 781973, 7 pages, 2015.

[2] J. L. Fiedler, A. D’Agostino, and C. Sununtnasuk, A Rapid Initial Assessment of the Distribution and Consumption of Iron-Folic Acid Tablets through Antenatal Care in Nepal, WHO, Geneva, Switzerland, 2015.

[3] W. Guideline, Daily Iron and Folic Acid Supplementation in Pregnant Women, World Health Organization, Geneva, Switzerland, 2012.

[4] T. T. Mohammed Akibu, A. Amano, M. Besho, S. Grutzmacher, and M. Tadese, "Adherence to prenatal iron-folic acid supplementation in low- and middleincome countries (LMIC): a protocol for systematic review and meta-analysis," BMC Systematic Reviews, vol. 7, p. 107 5, 2018.

[5] FMOH and FMoHoE, National Guideline for Control and Prevention of Micronutrient Deficiencies, Federal Ministry of Health of Ethiopia (FMOH), Addis Ababa, Ethiopia, 2016.

[6] M. T. Brown and J. K. Bussell, "Medication Adherence: WHO Cares?” Mayo Clinic Proceedings, vol. 86, no. 4, pp. 304-314, 2011.

[7] Demographic and Health Survey, Addis Ababa, Ethiopia and Calverton, Central Statistical Agency and ICF International, Maryland, USA, 2011.

[8] Federal Democratic Republic of Ethiopia, "Demographic and health survey 2016: key indicators report," The DHS Program ICF, vol. 363, p. 364, 2016.

[9] D. Vancampfort, J. Mugisha, J. Richards, M. De Hert, M. Probst, and B. Stubbs, "Physical activity correlates in people living with HIV/AIDS: a systematic review of 45 studies," Disability and Rehabilitation, vol. 40, no. 14, pp. 1618-1629, 2018.

[10] W. Niguse and R. Murugan, "Determinants of adherence to iron folic acid supplementation among pregnant women attending antenatal clinic in Asella town, Ethiopia," International Journal of Therapeutic Applications, vol. 35, pp. 60-67, 2018.

[11] A. Arega Sadore, L. Abebe Gebretsadik, and M. Aman Hussen, "Compliance with iron-folate supplement and associated factors among antenatal care attendant mothers in Misha district, south Ethiopia: community based cross-sectional study," Journal of Environmental and Public Health, vol. 2015, Article ID 781973, 7 pages, 2015.

[12] Y. Nisar, M. Dibley, and V. Aguayo, "Iron-folic acid supplementation during pregnancy reduces the risk of stunting in children less than 2 years of age: a retrospective cohort study from Nepal," Nutrients, vol. 8, no. 2, p. 67, 2016.

[13] B. Gebreamlak, A. F. Dadi, and A. Atnafu, "High adherence to iron/folic acid supplementation during pregnancy time among antenatal and postnatal care attendant mothers in Governmental Health Centers in Akaki Kality Sub city, Addis
Ababa, Ethiopia: hierarchical negative binomial Poisson regression," PloS One, vol. 12, no. 1, 2017.

[14] T. S. Kiwanuka, S. Ononge, P. Kiondo, and F. Namusoke, "Adherence to iron supplements among women receiving antenatal care at Mulago National Referral Hospital, Uganda-cross-sectional study," BMC Research Notes, vol. 10, no. 1, p. 510, 2017.

[15] B. Taye, G. Abeje, and A. Mekonen, "Factors associated with compliance of prenatal iron folate supplementation among women in Mecha district, Western Amhara: a cross-sectional study," Pan African Medical Journal, vol. 20, no. 1, 2015.

[16] S. Godara, R. Hooda, S. Nanda, and S. Mann, "To study compliance of antenatal women in relation to iron supplementation in routine ante-natal clinic at a tertiary health care centre," Journal of Drug Delivery and Therapeutics, vol. 3, no. 3, pp. 71-75, 2013.

[17] P. Lacerte, M. Pradipasen, P. Temcharoen, N. Imamee, and T. Vorapongsathorn, "Determinants of adherence to iron/ folate supplementation during pregnancy in two provinces in Cambodia," Asia Pacific Journal of Public Health, vol. 23, no. 3, pp. 315-323, 2011.

[18] E. Ugwu, A. Olibe, S. Obi, and A. Ugwu, "Determinants of compliance to iron supplementation among pregnant women in Enugu, Southeastern Nigeria," Nigerian Journal of Clinical Practice, vol. 17, no. 5, pp. 608-612, 2014.

[19] S. Gebremedhin, A. Samuel, G. Mamo, T. Moges, and T. Assefa, "Coverage, compliance and factors associated with utilization of iron supplementation during pregnancy in eight rural districts of Ethiopia: a cross-sectional study," BMC Public Health, vol. 14, no. 1, p. 607, 2014. 